\title{
Application-wise nanostructuring of anodic films on titanium: a review
}

\author{
Maria Vittoria Diamanti*, Marco Ormellese and MariaPia Pedeferri \\ Department of Chemistry, Materials and Chemical Engineering 'Giulio Natta', Politecnico di Milano, \\ Via Mancinelli 7, 20131 Milan, Italy
}

(Received 28 April 2014; final version received 12 December 2014)

\begin{abstract}
The interest in titanium and its oxides keeps growing on account of their peculiar engineered properties, which find applications in several fields, from architecture to bioengineering, from automotive to photovoltaic cells and photocatalytic devices, as well as to produce self-cleaning surfaces. This review intends to provide an overview of anodic oxidation treatments currently applied to form nanostructured oxide layers on titanium, with special reference to their whole range of applications. The different procedures and parameters of anodic oxidation will be described, giving information on the main oxide characteristics achievable: thickness, morphology, structure and composition. An analysis of the fields of application associated with specific oxide characteristics will be provided, in order to highlight the variety of properties that can be obtained, and the importance of tuning such properties as a function of the specific application.
\end{abstract}

Keywords: titanium oxide; anodic films; functional oxides; surface nanostructuring

\section{Why titanium}

As thoroughly described by Leyens and Peters in a comprehensive survey of titanium and its alloys,[1] the use of titanium is pushed by a synergy of chemical and mechanical properties that make it suitable for use not only in the production of aerospace [2] and biomedical components,[3,4] but also in chemical and oil industries,[5] automotive,[6,7] military,[8,9] architecture and jewellery.[10] The properties that account for this extremely wide range of applications are high specific mechanical strength (ensured by a high mechanical resistance combined with a low density), low thermal conductivity, low expansion coefficient, outstanding corrosion resistance and biocompatibility. Furthermore, all surface-related properties of this metal and its alloys - namely, aesthetic appearance, corrosion resistance and interactions with the working environment, including human body - can be fine-tuned as a function of the final application desired by oxidising the metal surface, which is generally performed by anodic oxidation.

This process consists of the production of an oxide layer on the surface of a metal; this treatment is generally applied to the so-called valve metals: $\mathrm{Al}, \mathrm{Hf}, \mathrm{Nb}$, Ta, Ti, W, $\mathrm{Zr}$, i.e. metals that form oxides with ionic conduction and almost perfect electrical insulation, allowing their use in electronics as capacitors, semiconductor insulators and tunnel junctions.[11] Their oxidation is allowed by ion migration through the oxide and follows a

*Corresponding author. Email: mariavittoria.diamanti@polimi.it 


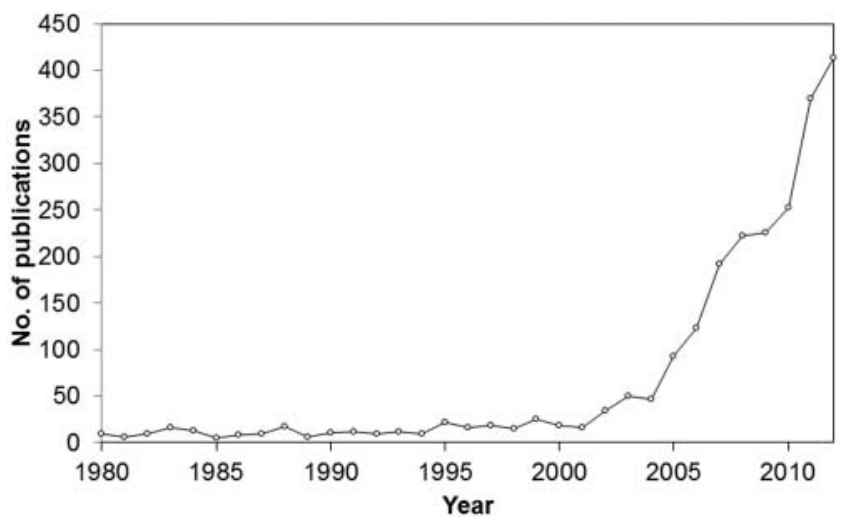

Figure 1. Number of articles published yearly on titanium anodising. Source: ISI Web of Knowledge.

high field law, as proposed by Guntherschulze and Betz (Equation 1):

$$
i=i_{0} e^{\beta E}
$$

where $i$ is the formation current density, $i_{0}$ its initial value, $\beta$ a high field constant (in $\mathrm{cm} / \mathrm{V}$ ) and $E$ the field strength, equal to the ratio between potential drop across the film, $\Delta U$, and film thickness, $d .[12]$

Concerning specifically titanium, scientific interest towards its oxidation has grown exponentially in the last decade, as proved by the rapid increase in the number of articles dealing with titanium anodising (Figure 1). This is due to constant improvements in the knowledge and control of anodising processes that led - and are still leading - to new oxide morphologies, compositions and functionalities, thereby expanding the area of possible application of anodic titanium oxides. For instance, morphological modifications may lead to the production of porous oxides, with porosity from tens of nanometres to the micrometre range, while oxide composition can be altered from stoichiometric $\mathrm{TiO}_{2}$ by adding several types of ions - from transition metals to phosphates, to rare earths - in order to functionalise the oxide layer with increased corrosion and wear resistance, or better biocompatibility and photoactivity.

The following paragraphs will first offer a panoramic view of anodising treatments, followed by a list of oxide features that can be fine-tuned by anodic oxidation, and of deriving applications.

\section{Anodic oxidation}

Titanium is naturally covered by a passive film, few nanometres thick, whose thickness can be increased by oxidation methods (mainly, by thermal or electrochemical processes) up to hundreds of nanometres, or in some particular cases to hundreds of micrometres. When compact films are produced, their thickness is linearly correlated to the applied voltage, which gives the possibility to extrapolate the oxide growth rate by measuring the oxide thickness by optical methods, as reported in most literature works, $[13,14]$ or by 
coulometric or impedance measurements.[15] Yet, only over the last few decades a good control of the anodising process has been achieved, which is of fundamental importance in the development of engineered $\mathrm{TiO}_{2}$ surfaces.

Anodising consists of polarising titanium by imposing a current flow between the titanium specimen and counterelectrode inside a suitable electrolytic solution; this causes metal atoms to oxidise to $\mathrm{Ti}^{4+}$ ions, which then combine with oxygen (or oxygencontaining) anions from the electrolyte to progressively form an oxide layer on the metal surface. Both an inward oxide growth and an outward oxide growth are usually considered, due to field-assisted ion migration under high field conditions, with a slight predominance of $\mathrm{O}^{2-}$ charge carriers across the oxide to reach the metal surface where $\mathrm{Ti}^{4+}$ cations are produced.[12]

The process is often performed under galvanostatic conditions - application of a constant current impulse, in the range of few $\mathrm{mA} / \mathrm{cm}^{2}$ up to hundreds of $\mathrm{mA} / \mathrm{cm}^{2}$, until the desired cell voltage or a determined charge is reached - or by a potential sweep, with anodising rates generally in the range $1 \mathrm{~V} / \mathrm{s}$ to $1 \mathrm{~V} / \mathrm{min}$. In both cases, a period of maintenance and stabilisation can be applied at a constant cell voltage: this step is particularly important when the production of nanotubular oxides is desired, as described in more details in Section 2.2. Figure 2 reports an overview of possible results obtained as a function of applied cell voltage. Several possible morphologies can be produced, which depend both on cell voltage and electrolyte composition, as described in the following sections.

Based on oxide characteristics, three main types of anodic oxidation processes can be identified: traditional anodising - thin compact films showing interference colours; anodising in a fluoride containing electrolytes, causing the growth of nanotubular oxides; and high-voltage anodising, also called anodic spark deposition (ASD) or plasma electrolytic oxidation (PEO) or micro-arc oxidation (MAO).

Process parameters deeply affect not only the oxide morphology, but also its structure: amorphous films - or more precisely, prevalently amorphous oxides - are generally obtained, but crystallites may nucleate in the amorphous matrix. Partial nanoscale crystallisation, focused at the metal-oxide interface, takes place in most oxides, but the extent is so limited that it cannot be observed by typical X-ray diffraction or Raman

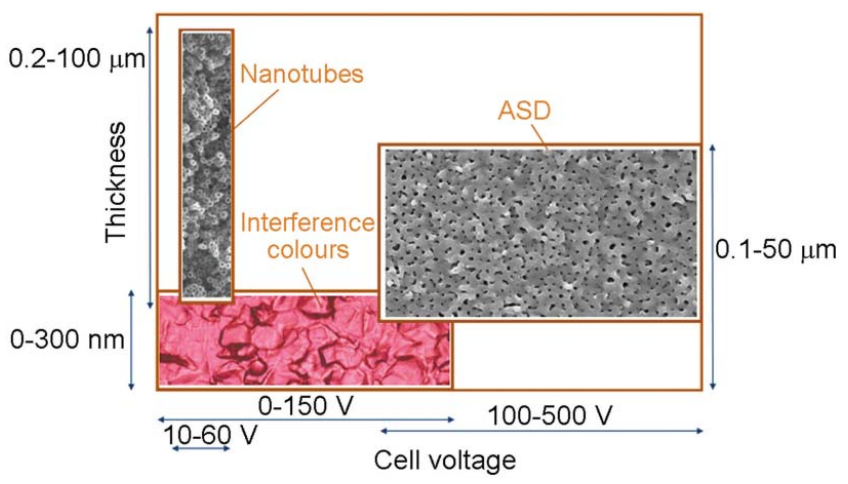

Figure 2. Map of anodising techniques as a function of applied voltage, and related range of oxide thickness. Adapted with permission from [3], (C) 2011, WICHTIG Editore SRL. 

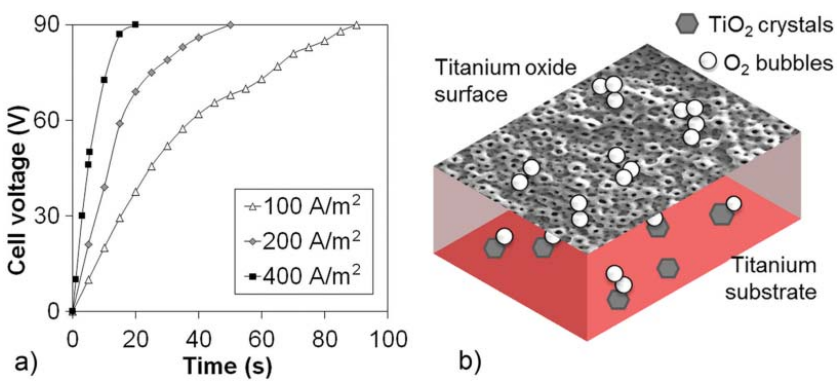

b)

Figure 3. Anodising ratio (V/s) decreases if a low current density is applied (a) and owing to the onset of parasitic $\mathrm{O}_{2}$ evolution reactions (b). Data in part (a) refer to titanium anodising in $\mathrm{H}_{2} \mathrm{SO}_{4}$ $0.5 \mathrm{M}$ : experimental details are described elsewhere.[18]

analyses. In contrast, by increasing the applied voltage over a given threshold specifically, by causing the oxide dielectric breakdown - a consistent oxide crystallisation can be achieved, as documented in several research works; the electrolyte activity and electric field developed into the oxide both influence the voltage threshold.[16,17]

The phenomenon is usually associated with oxygen evolution at the metal surface during anodising, made possible by the electronic conductivity of crystal domains (Figure 3; unpublished data on titanium anodising in diluted sulphuric acid; a detailed experimental procedure is reported in our previous work [18]); gas formation is not considered to be detrimental to oxide growth, but it acts as a parasitic process slowing down the anodising rate and increasing the power consumption. At first, anatase starts to crystallise, followed by an increase in size and number of crystallites and eventually their transformation into rutile.[18,19] Crystallites nucleation is the result of an early ASD initiation; as the process intensifies, the oxide thickness is strongly increased and interference colours are lost, as will be described in the next section.

\subsection{High-voltage anodising: anodic spark deposition}

ASD diverges from traditional anodising for a high cell voltage and current density are generally employed, in order to produce a microplasma state: this makes ASD by far the most onerous anodising technique.

The mechanism can be briefly described as follows. The initial oxide layer formed at a low voltage during the first stages of ASD creates a compact dielectric barrier: this prevents the ionic current from further flowing through the oxide itself. If the dielectric breakdown voltage is exceeded, the barrier is overcome, allowing for further oxidation; this condition is verified, thanks to the growing oxide defectiveness.

In fact, since the current flow is obstructed by the oxide, the whole available current concentrates in few weak points - e.g. defects or localised stress states - which produce a less effective barrier to current: the electric field reaches locally extremely high values, causing atom ionisation and a localised microplasma state, with kinetic temperatures up to $7700{ }^{\circ} \mathrm{C} .[20,21]$ The dielectric breakdown is accompanied by a cracking noise and sparking, i.e. small electric discharges that last few milliseconds and move along the whole surface, creating electric arcs, as the microplasma state moves from one weak point to 
another. The high energies involved in sparking cause damage to adjacent oxide areas which were still intact, and therefore cause the process to extend over the whole anodic surface.

A crucial characteristic is attributed to this process: an increased cationic mobility, which causes ions from the electrolyte to be incorporated into the oxide during plasma quenching. In fact, most applications of ASD coatings are based on the chemical modification of the growing oxide by an accurate choice of the electrolytic solution.[20] A non-exhaustive list of metal ions that can be introduced in the oxide composition include alkaline metals $(\mathrm{Ca}, \mathrm{Mg}, \mathrm{Sr})$, transition metals $(\mathrm{Co}, \mathrm{Fe}, \mathrm{Mn}, \mathrm{Nb}$, $\mathrm{Ta}$ ) and rare earths (Ce, Er). More appropriate examples are given in Section 3.3, with specific reference to the properties altered by some specific changes in oxide composition.

As far as morphology is concerned, this can result in microcracks departing from the sparking points, which are clearly visible as craters on the surrounding glassy surface. Craters' dimension varies from $200 \mathrm{~nm}$ to $2-3 \mu \mathrm{m}$ - the longer the sparking process, the bigger the mean crater size - and can be round-shaped, ellipsoidal or irregular, with elongated shapes, as shown in the examples of Figure 4 (data unpublished).[22,23] A nonnegligible coarse porosity, up to tens of micrometres, is also observed along the whole oxide thickness, usually associated with gas evolution on $\mathrm{TiO}_{2}$ crystal domains formed in the oxide due to the rapid ionisation and quenching. Porosity can be either functional to the coating (e.g. better lubrication of the surface in applications involving severe friction, and improved cell adhesion on the roughened surface) or detrimental (loss of mechanical resistance).[24]

As previously mentioned, crystallite nucleation may occur even at low voltages, as attested by oxygen evolution during the anodising process; nevertheless, such nanocrystals are usually embedded in the inner layer of the oxide, close to the metal, and do not contribute to the oxide functionalities commonly attributed to crystalline $\mathrm{TiO}_{2}$. Conversely, ASD-induced crystallisation leads initially to the formation of metastable anatase nuclei, which undergo allotropic transformation into rutile at higher voltages, probably owing to the increase in crystallite dimensions and to annealing effects. This extensive crystallisation is generally ascribed to compressive stresses arising from electrostriction, exerted by the electric field within the film and typically higher than $10^{6} \mathrm{~V} / \mathrm{cm}^{2} \cdot[19,23]$

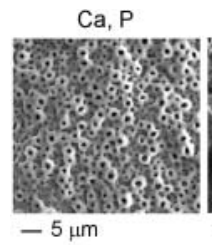

(a)

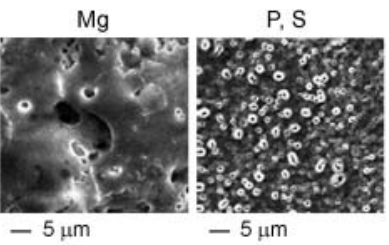

(b)

(c)

Figure 4. SEM images of oxides produced at high cell voltage in different electrolytes: for each one, the main electrolyte elements are indicated. Details on the titanium anodising process: (a) $350 \mathrm{~V}$, $20 \mathrm{~mA} / \mathrm{cm}^{2}, 0.015 \mathrm{M}$ calcium glycerophosphate/ 0.1 calcium acetate; ( b) $35 \mathrm{~g} / 1$ sodium phosphate/ $12 \mathrm{~g} / \mathrm{l}$ magnesium acetate; c: $200 \mathrm{~V}, 80 \mathrm{~mA} / \mathrm{cm}^{2}, 0.25 \mathrm{M}$ phosphoric acid/0.5 M sulphuric acid. 


\subsection{Nanostructured porous oxides}

The need for surface nanostructuring comes from the possibility to increase the surface-tovolume ratio, a pushing requirement in the production of titanium oxides - and of functional materials in general - as it facilitates reactions and interactions between $\mathrm{TiO}_{2}$ and the surrounding media, which mainly occur on the surface or at the interface. The first obtaining of disordered nanoporous titanium oxides dates back to 1997,[25] and a few years later highly ordered arrays of $\mathrm{TiO}_{2}$ nanotubes were eventually obtained by using diluted HF as the electrolyte.[26,27] Since then, several modifications to nanotube morphology - diameter, length, wall thickness and smoothness - distribution and composition have been achieved, as summarised in several reviews,[28,29] achieving increases in specific surface area of at least one or two orders of magnitude compared to the nominal one (Figure 5).

Such discrete and hollow tube-like features can be created on titanium through a simultaneous growth of a compact anodic oxide and its localised dissolution due to the presence of fluoride ions, by which $\mathrm{Ti}^{4+}$ ions are complexed to form water-soluble $\mathrm{TiF}_{6}{ }^{2-}$ species; moreover, the formed $\mathrm{TiO}_{2}$ layer is also chemically attacked and dissolved by $\mathrm{F}^{-}$.

To avoid the complete oxide dissolution, the $\mathrm{F}^{-}$concentration must be controlled in a narrow range, higher than $0.05 \%$ and lower than $1 \%$ by weight. The equilibrium between oxide growth and localised dissolution defines the peculiar nanotubular morphology and regulates the maximum oxide thickness achievable.[28-31]

Anodising conditions to achieve this peculiar morphology are strict: the electrolytic bath should contain fluoride ions (in few cases, chloride ions were found to be effective as well), usually in the form of $\mathrm{HF}, \mathrm{NaF}, \mathrm{KF}$ or $\mathrm{NH}_{4} \mathrm{~F}$ additions, and the cell voltage should normally lie between 10 and $60 \mathrm{~V}$, with values close to $20 \mathrm{~V}$ in aqueous electrolytes and higher in organic electrolytes. The maintenance time, i.e. the length of the anodising process after the desired cell voltage is reached, spans from tens of minutes to several hours. These parameters define the final morphological features, among which tube diameter and length play the key role in tuning the oxide efficiency for the chosen application. In fact, tube length depends on a growth-dissolution equilibrium; therefore, the more the solution aggressiveness, the shorter the nanotubes: in acidic media only a few hundred nanometres of film thickness can be produced, while second-generation nanotubes reach some micrometres of length: this is achieved in aqueous electrolytes by controlling the $\mathrm{pH}$ up to neutrality to reduce the oxide dissolution rate.

Finally, in non-aqueous, polar organic electrolytes - e.g. in ethylene glycol or dimethyl sulphoxide - third-generation nanotubes are produced, whose length can be increased to more than $100 \mu \mathrm{m} .[29-31]$

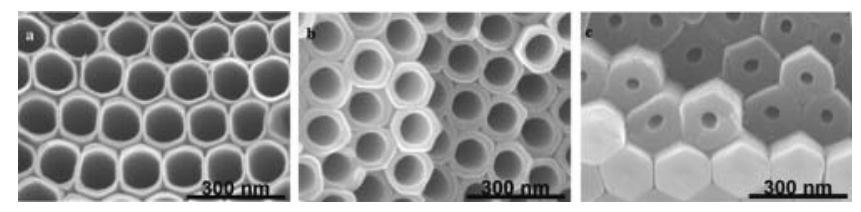

Figure 5. SEM images of close-packed hexagonal $\mathrm{TiO}_{2}$ nanotubes shown in Figure 1(d) and taken from the upper part of the layer (a), from the middle (b) and from the bottom of the layer (c). Reprinted with permission from [31] ๔ 2007, John Wiley and Sons. 
$\mathrm{TiO}_{2}$ nanotubes generally present an amorphous structure, although some germs of crystallisation may be found in tube walls, as described by Beranek et al.[32] If a crystalline oxide is desired - owing to a superior range of functionalities ensured by $\mathrm{TiO}_{2}$ crystal phases - nanotubes can be annealed at temperatures ranging from $300{ }^{\circ} \mathrm{C}$ to $900{ }^{\circ} \mathrm{C}$ as a function of the crystal structure desired, being anatase formation favoured below $500{ }^{\circ} \mathrm{C}$, while conversion to rutile is achieved above $550{ }^{\circ} \mathrm{C}$.[29]

\section{Application-wise tuning of oxide properties}

\subsection{Crystal structure}

\subsubsection{Crystal structures and their effect on optical properties}

Anodic oxides may present amorphous, crystalline or partially crystalline structures, depending on process parameters. A first distinction has to be made between crystalline (anatase, rutile and brookite phases) and amorphous $\mathrm{TiO}_{2}$, which is related to optical properties: amorphous films are transparent, while crystal phases generally show a whitish colour (less and less white with increasing content of impurities). Most importantly, the presence of a transparent film on a metallic - i.e. highly reflective - substrate produces interference phenomena; therefore, the surface appears differently coloured with hues that depend on the oxide thickness, and its hue can therefore be tuned by choosing suitable parameters of the oxidation process, which can be performed either by anodising or by thermal or laser oxidation. $[33,34]$ Not only this effect adds aesthetical value to anodised titanium, vital for applications in architecture and jewellery, but also it provides an instrument to evaluate oxidation kinetics: in fact, the oxide thickness can be estimated from the surface colour, as described for the first time by Leopoldo Nobili in the first half of the nineteenth century.[35] Further information on thickness-colour relationship is provided in Section 3.4.

Furthermore, these films lie in the field of optical coatings, whose engineering opens applications in technological areas such as communication, sensing, imaging and display. To match the fast growth of their use in this field, high-quality and strict tolerances on optical response are required, which makes the control of production process vital. Moreover, the availability of a wide range of optical properties can increase the variety of functions that can be covered by such films, which justifies the need for oxides with different thicknesses, crystal structures, stoichiometry and chemical compositions.[36] Currently, most production processes applied for optical coatings consist of chemical vapour deposition (CVD) and physical vapour deposition (PVD) processes, which generally generate films with optimal purity and conformity, at the expense of ease of processing, as well as of equipment and operational costs. In this respect, the optimisation of anodic treatments to reach coatings with suitable optical quality and homogeneity would provide a competitive technique, allowing a reduction in production costs.

\subsubsection{Electronic properties \#1: photoactivity}

Crystalline oxides present a semiconducting behaviour: $\mathrm{TiO}_{2}$ is a wide band gap semiconductor $(3.2 \mathrm{eV}$ for anatase structure, $3.02 \mathrm{eV}$ for rutile structure), which means that ultraviolet (UV) light is sufficiently energetic to cause an electron to leave the 
semiconductor valence band and reach the conduction band. This charge separation and the consequent formation of electron-hole pairs is the basis for all photoactivated properties of titanium dioxide, as first discovered by Fujishima and Honda in 1972 while studying rutile-activated water splitting under UV irradiation.[37] Even after more than 40 years, photoelectrochemical water splitting induced by nanostructured anodic $\mathrm{TiO}_{2}$ is a subject of numerous research works.[38] Photogenerated electrons have a high reducing potential, and generally cause the photoreduction of oxygen and water molecules adsorbed on $\mathrm{TiO}_{2}$ surfaces; similarly, the strong oxidising power of holes induces the formation of hydroxyl radicals that either bind to the oxide surface or are desorbed and released in the surrounding environment.[39]

In this respect, amorphous oxides attract almost nil interest, while anatase has been proved to be the best performing crystal structure. Photoactivation of thin $\mathrm{TiO}_{2}$ films has attracted attention in particular for self-cleaning and antifogging surfaces [40,41]; the film thickness is required to be in the range of tens of nanometres in order to ensure film transparency and avoid the modifications of substrate aspect, especially in the case of glass (e.g. self-cleaning windows, anti-fogging rear view mirrors). Anodic $\mathrm{TiO}_{2}$ films with a crystalline structure mostly find applications in advanced oxidation processes of wastewater treatment and air purifiers, owing to the ability of accelerating the degradation of organic and inorganic substances adsorbed on the film surface by interacting with electron-hole couples and related reactive species (photocatalytic behaviour).[42-45]

Furthermore, crystalline, well-aligned $\mathrm{TiO}_{2}$ nanotube arrays are employed in photovoltaic cells to boost the efficiency of dye-sensitised solar cells (DSSCs).[46] Most DSSC anodes consist of $\mathrm{TiO}_{2}$ nanopowders, which clearly present the advantage of a high specific surface area (Figure 6); on the other hand, such wide surfaces also show some drawbacks, namely facilitated electron-hole couples recombination at grain boundaries and a zig-zag path that increases scattering.

Nanotubular structures enhance the surface area available for dye adsorption and, most importantly, they provide a straight path for faster and more efficient electron collection. $[47,48]$ Some aspects related to the device still need to be optimised, especially concerning light harvesting [49]: either back-illumination is used, compatibly with the poor transmittance of a catalyst-coated counter electrode, or a transparent layer of $\mathrm{TiO}_{2}$

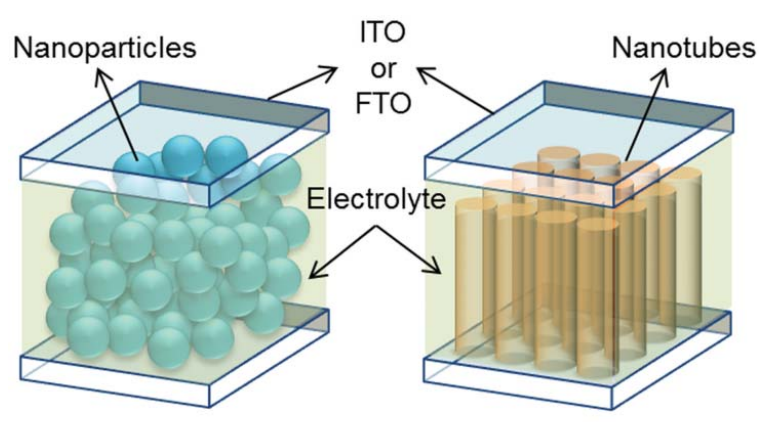

(a)

(b)

Figure 6. Comparison between DSSC geometries obtained with (a) $\mathrm{TiO}_{2}$ nanoparticles and (b) $\mathrm{TiO}_{2}$ nanotubes: in the latter case, a straight conduction path is available for photogenerated electrons to cross the photoanode and be collected. 
nanotubes must be obtained directly on conductive glass (by titanium sputtering and subsequent anodising, which is quite expensive) or transferred on it after production.[50]

\subsubsection{Electronic properties \#2: dielectric properties vs. ionic conductivity}

$\mathrm{TiO}_{2}$ oxides also find applications in the field of electroceramics, where the electrical behaviour is once again determined by the oxide structure. As previously cited, crystalline $\mathrm{TiO}_{2}$ belongs to semiconductors; furthermore, it presents changes in resistivity due to the chemisorption of gases (e.g. hydrogen, ethanol, ammonia, nitrogen dioxide), which paves the way for use as an active element in gas sensors.

This concerns not only gas sensors working under high-temperature conditions $\left(>400{ }^{\circ} \mathrm{C}\right.$ ), typical of ionic conductors such as $\mathrm{ZrO}_{2}$ and sub-stoichiometric $\mathrm{TiO}_{2}$ itself, but also room-temperature-active gas sensors (Figure 7).[51] Proposed low-temperature gas sensing mechanisms depend on the nature of gas - for instance, $\mathrm{H}_{2}$ diffuses into a $\mathrm{TiO}_{2}$ lattice acting as an electron donor [52] or forms $\mathrm{OH}$ groups at its surface, creating an electron-rich interface region while reducing gases tend to react with photogenerated ionised oxygen species produced on $\mathrm{TiO}_{2}$ by $\mathrm{UV}$ irradiation $\left(\mathrm{O}_{2}^{-}, \mathrm{O}^{-}, \mathrm{O}^{2-}\right)$, resulting in increased room temperature sensitivity.[53,54]

On the other hand, rutile can also present a high dielectric constant, $\varepsilon$, that increases with temperature, with average values in the range of $40-100[55,56]$ and up to 1000 on single crystals.[57] Rutile $\mathrm{TiO}_{2}$ with a combination of high $\varepsilon$, temperature stability and low dielectric loss attracts attention for applications as a gate dielectric for MOSFETs (metal oxide-semiconductor field-effect transistors).[58]

\subsubsection{Biocompatibility}

Finally, the presence of a specific $\mathrm{TiO}_{2}$ structure - i.e. once more the anatase crystal phase - is associated with improved osseointegration of titanium, which is generally exploited in dental implants by spark anodising the titanium abutment.[59-61] This effect is due to increased bone growth and decreased bacteria proliferation compared to the bare metal: as reported by Sollazzo et al.,[62] anatase specifically regulates some gene

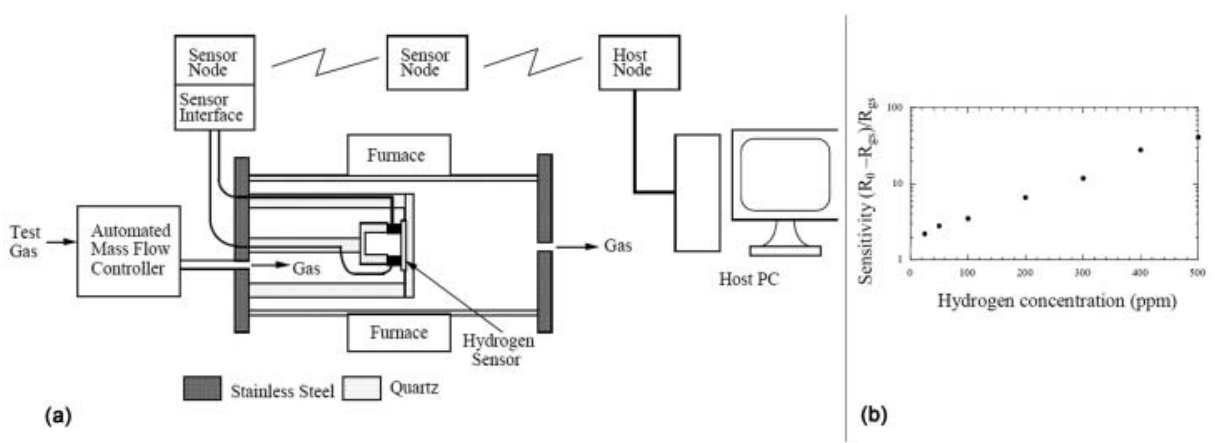

Figure 7. (a) Experimental setup for hydrogen sensing evaluation on $\mathrm{TiO}_{2}$ nanotubes and (b) hydrogen sensitivity of a $76 \mathrm{~nm} \mathrm{TiO}_{2}$ nanotube sensor at $290{ }^{\circ} \mathrm{C}$ for low hydrogen concentrations. Reprinted with permission from [52] ( 2003 , MDPI. 
expressions related to immunity which suppress foreign body recognition, which is critical in the grafting process. Anatase was also observed to act in vesicular transport, apoptosis and cell cycle regulation, producing modifications in the turnover of extracellular matrix components and in osteoblast proliferation. Moreover, anatase and rutile phases induce surface bioactivity by facilitating the formation of hydroxyapatite: this was first achieved on annealed titanium,[59] then on anodic films produced in $\mathrm{H}_{2} \mathrm{SO}_{4}$.[63]

\subsection{Morphology}

Anodic oxides present different morphologies, as thoroughly discussed in Section 2; basically, nanostructured anodic oxide films may (1) follow the underlying titanium substrate topography (smooth compact films) or (2) present some $100 \mathrm{~nm}$ to few $\mu \mathrm{m}$ wide craters, randomly disseminated on the surface or (3) grow in the form of self-assembled nanotubes with different tube shapes, orientations, thicknesses and diameters.[3] In particular, the first class of coatings are strictly required only when optical transparency plays a fundamental role, that is, in self-cleaning or corrosion-resistant films for architectural applications, where the material surface confers value to the structure not only in terms of functional properties, but also from an aesthetical perspective.

On the other hand, in the majority of applications where functional $\mathrm{TiO}_{2}$ films are desired, a key feature to achieve high efficiency is to produce controlled nanoscale morphological features, owing either to the specific surface texture or to the higher specific surface area or both.

\subsubsection{Enhancing efficiency through high specific surface area}

Photocatalytic reactions, gas sensing and photocurrent production, all these functionalities are enhanced by an increase in surface area, due to the larger number of active surface sites available for reactions. In this respect, $\mathrm{TiO}_{2}$ nanotubes undoubtedly present the optimal configuration: not only is the specific surface area of these nanoporous structures orders of magnitude higher compared to the nominal one, but it is also possible to detach them from the original titanium substrate and utilise them, for instance, as self-standing anodes for photovoltaic cells [50] or membranes for wastewater photocatalytic treatment.[64]

In fact, increasing the tube length of closed nanotubes improves their efficiency only at relatively low values (in the order of few micrometres): Figure 8 shows an example of photocatalytic degradation of a model organic dye, rhodamine $\mathrm{B}(\mathrm{RhB})$, under different nanotube thicknesses - from $800 \mathrm{~nm}$ to $1.4 \mu \mathrm{m}$, grown in the same electrolyte - as a function of the initial $\mathrm{RhB}$ concentration $\left(C_{0}\right)$. Data presented in Figure 8 were extracted and processed from a previous work.[44]

At low $C_{0}$, degradation increases linearly with dye concentration and similar results are obtained with differently anodised specimens, indicating that tube length is not fully exploited yet (same degradation for short and long nanotubes); conversely, above $10 \mu \mathrm{mol} / \mathrm{l}$ longer tubes are still able to increase dye adsorption and maintain a consistent degradation, while shorter ones reach saturation conditions - i.e. full coverage of $\mathrm{TiO}_{2}$ active sites.

On the other hand, an exceeding thickness is not proficient, as it would offer a resistance to pollutant absorption inside tubes - and subsequent adsorption on tube 

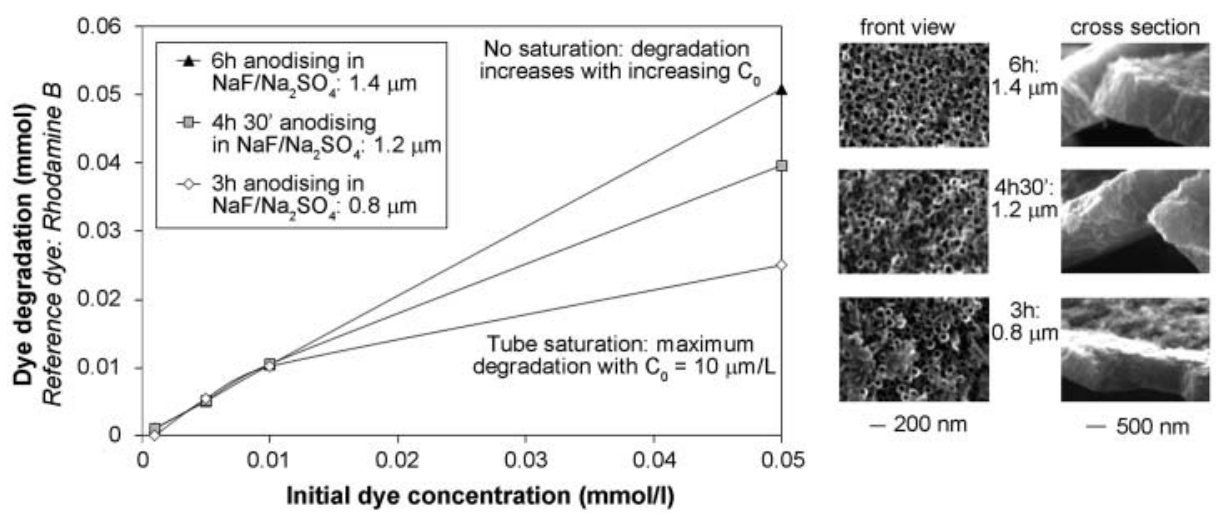

Figure 8. Degradation of a model organic dye in the presence of $\mathrm{TiO}_{2}$ nanotubes of different lengths, as a function of initial dye concentration ( $5 \mathrm{~h}$ of UV irradiation of $1 \mathrm{~mW} / \mathrm{cm}^{2}$ intensity), and related oxide morphology on the right observed by an SEM. Unpublished processing of data presented in a previous work.[44]

walls - due to difficulties in removing air from the inner part of the pore. Therefore, only the upper tube section is used, whose extension depends on the tube diameter and can be approximated to few micrometres, or less: this limit can be overcome in free-standing, flow-through membranes, where the entire tube length is exploited for photocatalytic reactions.[44]

\subsubsection{Cell response to nanotopography}

Besides photoactivated reactions, surface nanostructuring also covers a fundamental role in cell interaction with oxidised substrates.[65-67] For instance, Mendonca et al. reported an in vivo study demonstrating how nanoscale $\mathrm{TiO}_{2}$ coatings, especially in the form of anatase, promoted a mesenchymal stem cell commitment to osteoblast phenotype, thereby increasing bone-to-implant contact and association.[68] Several studies also support the influence of surface nanostructuring on cell response, involving both in vitro and in vivo testing on osteoblast specific gene expression, differentiation and mineralisation,[69-71] as well as cell adherence to the implant.[72,73] Specifically considering $\mathrm{TiO}_{2}$ nanotubes, the effect of surface nanostructuring - i.e. nanotube diameter - has been the subject of several recent research works, and results are still controversial. Lan et al. observed an increasing trend in fibroblast cell proliferation, together with an elongated flatten morphology, on nanotubular oxides with pore diameter ranging from 15 to $50 \mathrm{~nm}$ compared to flat titanium; yet, a sharp drop in proliferation was exhibited by $100-\mathrm{nm}$ diameter pores (Figure 9(A)).[74]

In a parallel work, the behaviour of osteoblasts and mesenchymal stem cells was studied by Frandsen et al. on a series of nanotube sizes, with diameters ranging from 30 to $100 \mathrm{~nm}$. Cell elongation increased as a function of nanotube diameter even above $50 \mathrm{~nm}$, indicating improved differentiation; on the other hand, cell proliferation and adhesion were maximised on 30-nm-diameter nanotubes (Figure 9(B)). This bivalent trend was attributed to protein adsorption patterns on the oxide surface, as they tend to change the number and placement as a function of surface topography.[75] 
(1)
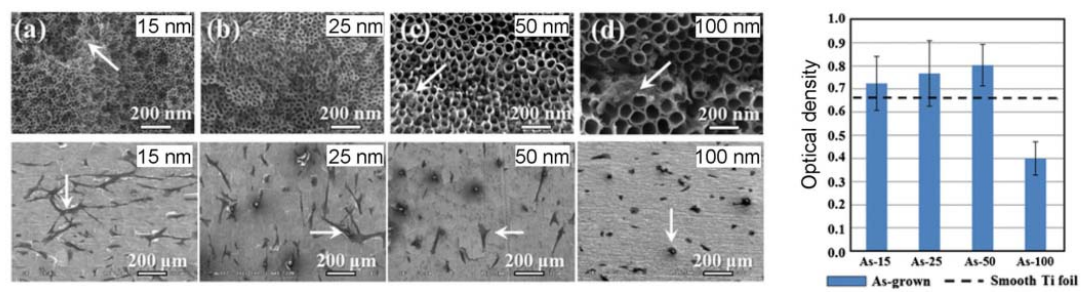

(3)

(a)

(4)
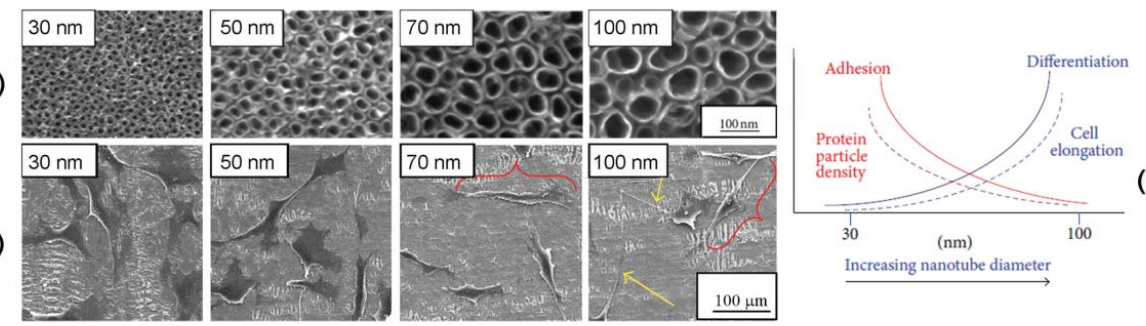

(6)

(b)

Figure 9. Effect of nanotube diameter on cell behavior. Top (A): (1) oxide morphology as a function of tube diameter and (2) related human fibroblast cell distribution after $24 \mathrm{~h}$ of culture; (3) optical densities measured after the culture of fibroblast cells. Modified from [74] @ 2013, Lan et al. Bottom (B): (4) oxide morphology as a function of tube diameter and (5) related osteoblast cell distribution after $24 \mathrm{~h}$ of culture; and (6) schematic illustration of the overall trends of nanocue effects on cell fate and morphology. The change in cell adhesion and growth without differentiation has the same trend as protein particle density, whereas that of differentiation has the same trend as cell elongation. Modified from [75] (c) 2013 Christine J. Frandsen et al.

\subsubsection{Drug delivery}

The nanotubular geometry is particularly suitable to build up a drug-delivery capsule, or a drug-eluding coating on the titanium implant.[76-78] Up to now, nanotube-based drug delivery has been restricted to few substances, e.g. bovine serum albumin, penicillin, gentamycin, streptomycin or vancomycin. Although it was possible to increase up to $450 \%$ the quantity of drug adsorbed by standard procedures compared to non-treated titanium, the release was also more pronounced, decreasing the potential long-term beneficial effect; to obtain a retarded release, vacuum impregnation of nanopores was successfully applied.[79] Finally, nanotubes can be engineered to further push this potentiality: for instance, Song et al. proposed the deposition of a hydrophobic cap on the tube opening, thus preventing undesired drug release before the cap is dissolved, which should be obtained by UV irradiation or X-ray radiation.[80]

\subsection{Composition}

Among anodised titanium components currently used at industrial level, several examples can be found of oxides with composition diverging from pure $\mathrm{TiO}_{2}$. This aspect is of great importance in three main application fields, that is, bioengineering, corrosion resistance and photoactivation - the latter including all aspects, from photocatalysis to water splitting to photovoltaic. 


\subsubsection{Biocompatible and antibacterial coatings}

Anodising titanium prosthesis and osteosynthesis devices implies the formation of an anatase layer: performing ASD in suitable environments, such as phosphate-, silicate- or calcium-rich electrolytes, generates $\mathrm{P}-$, Si- or Ca-doped crystalline oxides, providing a strong passivation to the surface as well as modifying surface properties to further improve biocompatibility, and eventually attaining a bioactive surface.

In general, phosphate electrolytes are the most frequently studied, owing to improvements in corrosion resistance combined with a biocidal effect induced by polyphosphates, elemental phosphorus or phosphides in the coating.[81,82] The introduction of silver in the oxide is also a critical research topic, as Ag-doped $\mathrm{TiO}_{2}$ significantly contributes to advances in the regulation of microbial colonisation and to reduce implantrelated infections, owing to its broad-spectrum bactericidal activity.[83] Ag-functionalised $\mathrm{TiO}_{2}$ films are mostly produced by chemical techniques (sol-gel, chemical deposition, precipitation-reduction), but ASD treatments have been developed as well, which consist of high-voltage anodising in silver acetate or silver nitrate-containing electrolytes.[84-86] In this respect, it is interesting to note that silver may pose a hazard not only to bacteria, as desired, but also to higher organisms (e.g. eukaryotic organisms). Still, several studies found that the form of addition of silver is of outmost importance, being silver ions responsible for significant toxicity, while the use of silver nanoparticles (AgNP) was found to produce higher cytotoxicity thresholds. As a consequence, the use of AgNP would allow to decrease the potential hazard connected with Ag-based antibacterial treatments.[87-89]

However, what mainly determined the success of ASD was the achievement of large improvements in the osseointegration and biocompatibility of titanium prosthetic implants by modifying the critical factors for implant-tissue interactions, that is, its surface chemical composition, topography and corrosion rate. The most important surface modification developed and investigated in this field is the formation of a Ca- and P-rich oxide by ASD in $\beta$-glycerol phosphate ( $\beta$-GP) calcium acetate electrolytes.[90,91] The resulting oxide consists of a thin $\mathrm{TiO}_{2}$ layer, a few micrometres thick, and an outer layer almost entirely composed of amorphous $\mathrm{Ca}-\mathrm{P}$ oxides: if a suitable $\mathrm{Ca}$-to-P ratio is obtained, this layer can then be converted into bioactive hydroxyapatite (HA) by hydrothermal treatment.[92-94]

Further evolutions of the ASD techniques report the direct obtaining of HA-coated $\mathrm{TiO}_{2}$ on Ti6Al4V by pulse anodising in acetate monohydrate (CA) and $\beta$-GP disodium salt pentahydrate at voltages higher than $450 \mathrm{~V}$.[95] In addition, an enhanced antibacterial activity and cell compatibility were attributed to titanium plates anodised by discharging in $\mathrm{Cl}$ salt solutions $\left(\mathrm{NaCl}, \mathrm{KCl}, \mathrm{MgCl}_{2}\right)$. Such functionalisation was ascribed to the surface formation of granular $\mathrm{TiCl}_{3}$ deposits and their slow hydrolysing to $\mathrm{HClO}$, whose peroxidation effects produce the antibacterial effect; the concomitant formation of anatase enhances cell adhesion and proliferation.[96,97]

\subsubsection{Corrosion and wear resistance for automotive and aerospace}

Titanium alloys are employed as lightweight, high-temperature and anticorrosive structural materials in aerospace, marine and automobile components - for example, in compressors and blades of gas turbine aircraft engines, wing structures, landing gear components, submarine propellers, springs, bolts and screws. In these fields, titanium-aluminium alloys are generally used, among which the most diffuse is Ti6Al4V, accounting for more than $50 \%$ of the Ti alloys production. In spite of an excellent mechanical resistance, high working 
temperature and good corrosion resistance, these alloys are usually characterised by low hardness, poor resistance to wear and limited load bearing capacity, owing to a low resistance to plastic shearing and limited work hardening behaviour. Moreover, a high friction coefficient is generally observed during dry sliding wear, either against a metal or against a ceramic counterpart, which increases surface shear and tensile stress components, inducing a strong tendency to galling.[98,99] Finally, oxidation resistance at high temperature is limited compared to commercial purity titanium grades due to the formation of a non-protective mixed scale of $\mathrm{Al}_{2} \mathrm{O}_{3}$ and $\mathrm{TiO}_{2}$.[100] Still, the mechanical resistance of pure titanium could be insufficient to withstand the heavy working conditions of mechanical components, especially in the presence of a creep: in fact, Ti6Al4V is still used in many hightemperature applications.

For these reasons, over the past few decades several surface modifications on titanium alloys have been developed and characterised,[101] among which ASD allows outstanding improvements of wear, high-temperature corrosion and thermal shock resistance while ensuring excellent substrate adhesion. Silicate and silicate-aluminate solutions are among the most used electrolytes employed to generate ceramic coatings that improve the tribocorrosion behaviour of TiAl alloys.[102,103] Coating effectiveness can be related to the incorporation of silicates in the ceramic coating, either increasing surface hardness or reducing its friction coefficient,[24,104,105] and consequently the adhesion between the component surface and counterpart, thus limiting wear and debris generation. One example of ASD coating produced on mechanical components (planar specimens as well as complex 3D geometries) is shown in Figure 10, where the oxide thickness and morphological features due to spark anodising (microcracks, craters) are highlighted.

On the other hand, ASD coatings may also exploit the presence of different species to improve surface properties, such as in the studies conducted by Rudnev et al.[106] In particular, the production of coatings in polyphosphate solutions of different metals was evaluated, leading, for instance, to mixed $\mathrm{Al}_{2} \mathrm{TiO}_{5}$ and $\mathrm{AlPO}_{4}$ phases with potentially improved heat resistance and insulating properties. Similarly, tantalum- and niobiumbased coatings on titanium could also produce an increase in metal corrosion resistance as well as biocompatibility.[107,108]

\subsubsection{Oxide doping to reduce band gap: visible light photoactivity}

Considerable effort has been dedicated to $\mathrm{TiO}_{2}$ band gap engineering, in order to improve solar spectrum exploitation in its photoactivation (photocatalytic reactions, self-cleaning,

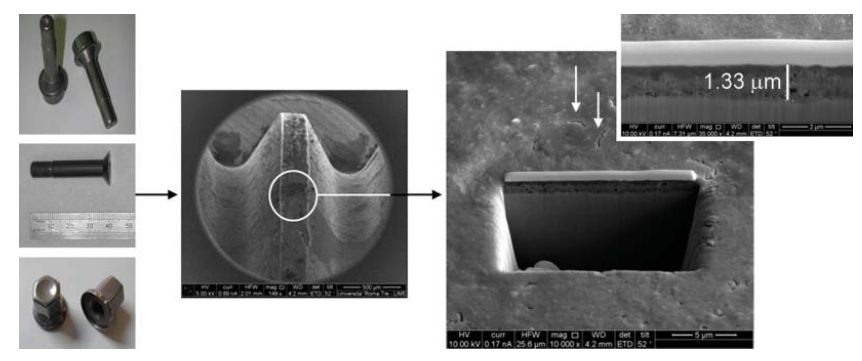

Figure 10. Example of ceramic coating obtained on Ti6Al4V by ASD and subjected to barrel finishing to improve corrosion and wear resistance. FIB-SEM analyses adapted with permission from [24] (c) 2003, Elsevier Ltd. 
photovoltaic) that otherwise would benefit only from UV radiation. To meet this aim, doping is generally performed by introducing secondary electronically active species into the lattice, which forms accessible energy levels within the band gap and also allows photoactivation with higher wavelength radiation - specifically, that of visible light.

This modification would not only improve the photonic efficiency of $\mathrm{TiO}_{2}$ exposed to sunlight, where UV only covers $8 \%$ of the spectrum, but also extend the use of materials such as photocatalytic paints and self-cleaning coatings to indoor environments, where the use of UV light is considered harmful to health.[109]

In this process, it appears easier to substitute the $\mathrm{Ti}^{4+}$ cation in $\mathrm{TiO}_{2}$ with other transition metals, and it is more difficult to replace the $\mathrm{O}^{2-}$ anion due to differences in charge states and ionic radii. For instance, titanium can be replaced by other metal ions, such as $\mathrm{W}, \mathrm{V}, \mathrm{Ce}, \mathrm{Zr}, \mathrm{Fe}, \mathrm{Cr}, \mathrm{Ni}$ and $\mathrm{Cu},[110,111]$ which is most commonly performed by ion implantation. This procedure has some drawbacks, specifically thermal instability of the oxides, increase in recombination centres and related decrease in charge carriers, and need for expensive equipment for ion implantation. Alternatively, metal ion doping can be performed directly by ASD by introducing $\mathrm{Co}, \mathrm{Fe}, \mathrm{Mn}, \mathrm{Ni}$ and other metal ions. Such modifications were observed to improve the oxide catalytic activity towards the oxidation of $\mathrm{CO}$ to $\mathrm{CO}_{2}$, as well as to modify the oxide band gap with consequent alteration of its photocatalytic activity.[112-114]

On the other side, non-metal doping can be more easily accomplished by using B, C, N, $\mathrm{F}, \mathrm{S}, \mathrm{Cl}$ and $\mathrm{Br}$, being nitrogen, carbon and halogen doping the most investigated systems.[115-117] In fact, Asahi et al. first achieved an effective band gap alteration by nitrogen doping, and showed the optical absorption of such doped oxide in the visible light region.[118] Currently, the most utilised method for nitrogen doping of anodic oxides is annealing in a suitable atmosphere (nitrogen, urea or ammonia).[44,118,119]

\subsubsection{Memristive behaviour of non-stoichiometric oxides}

$\mathrm{TiO}_{2}$ films generally present an insulating behaviour, but the presence of oxygen vacancies at the metal-oxide interface introduces a peculiar electrical response as circuital elements known as memristance [120]: in some anodic oxides with nanoscale thickness resistivity is a function of current previously travelled through the oxide in the past (from where the memristor term arises), thus showing a bias-dependent bipolar switching response to current.[121,122] This is made possible in $\mathrm{TiO}_{2}$ by two factors: its defective nature, with oxide stoichiometry varying from $\mathrm{TiO}_{2}$ to $\mathrm{TiO}_{2-x}$, and the possibility of limiting its thickness to few tens of nanometres, as memristance is inversely proportional to the square of the oxide thickness.[123] Memristive devices are opening the way to a new generation of transistor-like devices with easy scaling-down possibilities, as well as nonvolatile memories with fast access and improved data density, and finally to the introduction of synapses in artificial neural networks.[124]

\subsection{Thickness}

As previously cited, anodic oxidation can be used to confer to the surface a coloured appearance, thanks to the formation of an oxide layer, up to few hundred nm thick. First investigations on the formation of interference colours on metals date back to Evans,[125] 
whose attention was caught by the colours arising from the corrosion of metals and consequent generation of thin oxide layers on the metal surface. The phenomenon was immediately ascribed to interference, and the colour observed was found to be a visual representation of the thickness of the transparent oxide film that provoked it. In more detail, colours are generated by a multiple beam interference of transparent films on metals as follows: the film surface reflects with an angle $\theta_{1}$ only a part of the incident white light, while the remaining part is refracted with an angle $\theta_{2}$ inside the film as given by Snell's law (Equation (2), where $n_{\text {air }}$ and $n_{\mathrm{TiO} 2}$ represent the refractive indexes of air and titanium dioxide, respectively), and reflected by the metal underneath:

$$
n_{\mathrm{air}} \sin \theta_{1}=n_{\mathrm{TiO}_{2}} \sin \theta_{2}
$$

Colour hue is then determined by light components strengthened by exiting the oxide in phase (constructive interference) and by those weakened or cancelled by exiting in opposition of phase, and this in turn depends on their optic path, that is, on the oxide thickness $d$ and refractive index, following Bragg's interference law:

$$
n_{\mathrm{TiO}_{2}} \lambda=2 d \sin \theta
$$

where $\lambda=$ radiation wavelength giving a constructive interference and $\theta=$ angle of incidence of light. These relations can be applied either to obtain a desired colour by anodising a surface - or, in a specular way, to have an indirect measurement of anodic film thickness - by determining the position of interference maxima and minima that characterise the surface reflectance spectrum (Figure 11).

The anodising parameter mostly affecting the oxide thickness is the applied voltage: a linear relationship between cell voltage and oxide thickness is usually obtained, with growth rates ranging from 1.5 to $3 \mathrm{~nm} / \mathrm{V}$ depending on other anodising parameters (Figure 12) - current density, electrolyte composition and temperature, stabilisation, surface treatment, base metal composition.[10,126,127]

In the 1960s, the operating conditions for achieving determined colour hues had already been specified for anodising in diluted phosphoric and sulphuric acid, and an

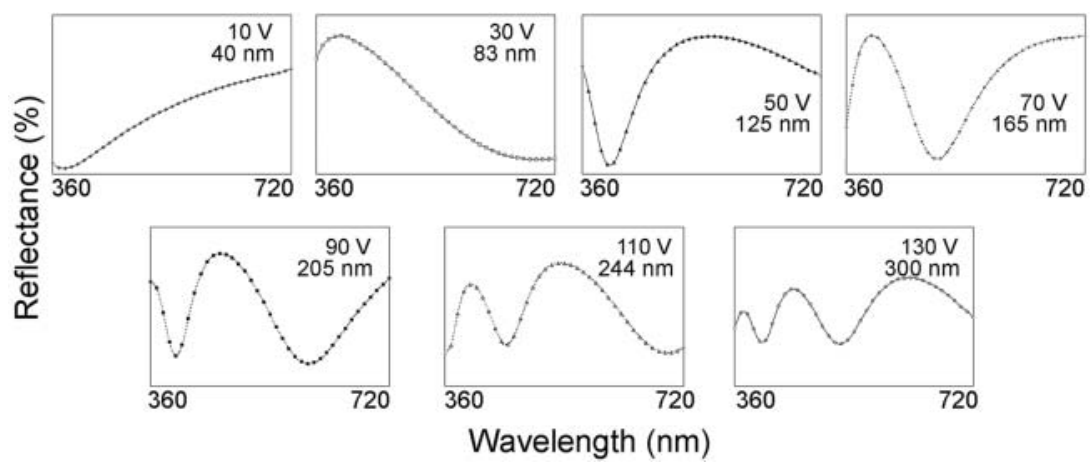

Figure 11. Reflectance spectra of the Ti6Al4V alloy anodised with a cell voltage in the range $10-130 \mathrm{~V}$ in $\mathrm{H}_{3} \mathrm{PO}_{4}$, showing different interference peaks, and related oxide thicknesses. Adapted with permission from [10] (C) 2012, John Wiley and Sons. 


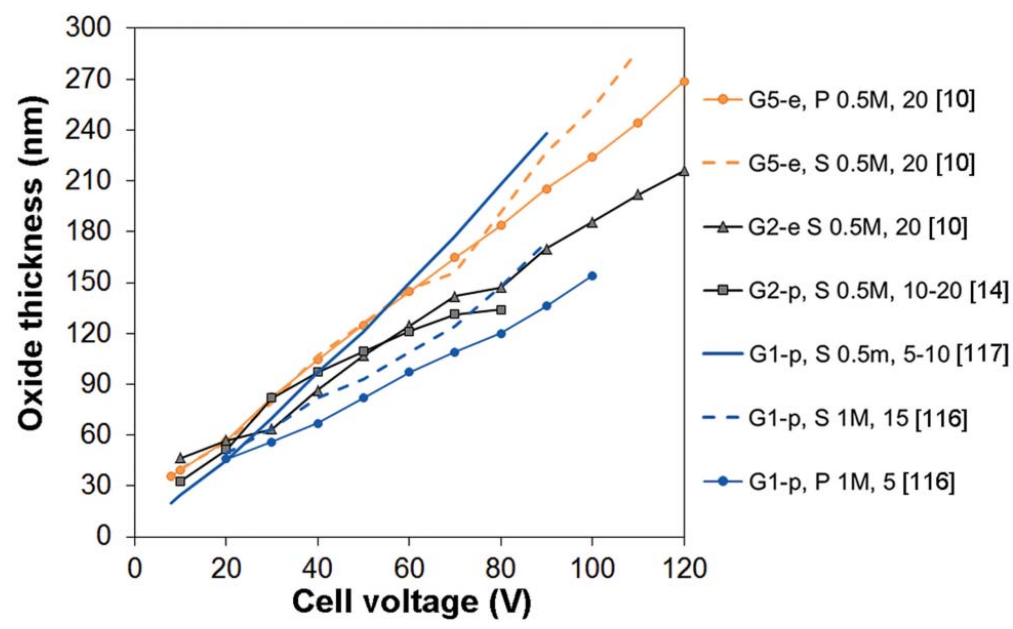

Figure 12. Voltage-thickness relationship of galvanostatically grown anodic oxides. Labels contain: metal composition: Ti grade $1(\mathrm{G} 1), 2(\mathrm{G} 2)$ or $5(\mathrm{G} 5)$, and surface finishing (p: polished, e: etched); electrolyte ( $\mathrm{S}: \mathrm{H}_{2} \mathrm{SO}_{4}, \mathrm{P}: \mathrm{H}_{3} \mathrm{PO}_{4}$ ); and current density applied (in $\mathrm{mA} / \mathrm{cm}^{2}$ ). Data extracted and combined from literature works.[10,14,126,127]

'instant colour writing' was developed by using a platinum or lead wire - sheathed in a glass tube and functioning as a counterelectrode - as a pencil on a titanium sheet.[128] Chromatic effects could also be localised by screening a part of the surface and subjecting the remaining part to oxidation; furthermore, the invisible aspects of certain physical or chemical phenomena were brought to light on titanium - the so-called 'appearances' concerning phenomena that had either already taken place (field appearances) or that were taking place (movement appearances) during image formation on the surface, as described and realised by Pedeferri [129]:

Although such pictures describe an infinitely small, complex world created by nanotechnologies, they transmit astral visions and feelings of lightness, of being suspended weightless.

These effects are of particular interest for two reasons: the aesthetic qualities they confer to oxidised titanium, essential for design applications, and the already cited indirect measurement of nanometric oxide thickness, which can be pursued by analysing them: the cross-linking between electrochemistry, nanosciences and art brought Pedeferri the Science pour l'Art prize (Paris, 1989) for his work on titanium colouring. Fine examples of decorative arts can also be found in jewel production since the second half of 1900, for instance, the bangle bracelet by JAR (Joel Arthur Rosenthal, 1987), James Rivière's jewels produced in collaboration with Pedeferri, and the latest jewel collection produced on the occasion of the exhibition 'Precious Titanium', held in Milan, Triennale, in July-August 2010 (Titani Preziosi).[130]

Surface colouring is exploited not only in architectural and design products, but also in biomedical ones. In fact, coding schemes are used to identify osteosynthesis plates, screws, and instrumentation to simplify matching among mating components, owing to the plurality of sizes required to have optimal attachment to the underlying support tissue for 
each patient: it is thus possible for operating room personnel to quickly select the parts and verify their compatibility.[131] On the other hand, colour control in architecture requires extremely strict tolerances on hue and saturation, as well as high homogeneity over wide surface areas - even of the order of $1 \mathrm{~m}^{2}$.

A suitable rationalising and knowledge of the anodising process are therefore vital so as to obtain well-defined thicknesses as a function of process parameters as well as their surface texture and substrate composition (i.e. commercial purity grade titanium or its alloys): an extremely robust process is therefore needed to transfer such processes to the logics of series production.

\section{Conclusions}

As discussed in this brief overview dedicated to titanium anodising, titanium dioxide surface science still needs to be more deeply explored, since any improvement in the control of $\mathrm{TiO}_{2}$ surface properties can boost the material efficiency in related applications, and further broaden its field of use. An almost infinite number of chemical, electrochemical and physical techniques have been adapted and applied to the production of titanium dioxide layers on different substrates. Nevertheless, the variety of oxide features that can be obtained by anodising in a relatively easy, industrially scalable way, without the need for expensive equipment, still accounts for the high potential of such techniques, and for the effort dedicated to understand its most intricate details. Future challenges in this field surely include the most engineered aspects of titanium oxides, with particular attention to the simultaneous control of oxide crystal structure and stoichiometry. This would pave the way to applications in optical and electrical devices such as communication, sensing, imaging and display devices, memristive elements, dielectrics, electrochromic devices, batteries - where the precision and homogeneity of oxide characteristics are the key for the successful development of high-efficiency devices with tunable properties.

\section{Disclosure statement}

No potential conflict of interest was reported by the authors.

\section{References}

[1] Leyens C, Peters M, editors. Titanium and titanium alloys. Fundamentals and applications. Weinheim: Wiley-VCH; 2003.

[2] Boyer RR. An overview on the use of titanium in the aerospace industry. Mater Sci Eng A. 1996;213:103-114.

[3] Diamanti MV, Del Curto B, Pedeferri MP. Anodic oxidation of titanium: from technical aspects to biomedical applications. J Appl Biomater Biomech. 2011;9:55-69.

[4] Rack HJ, Qazi JI. Titanium alloys for biomedical applications. Mater Sci Eng C. 2006;26:1269-1277.

[5] Schutz RW, Baxter CF, Boster PL. Applying titanium alloys in drilling and offshore production systems. JOM. 2001;53:33-35.

[6] Sachdev AK, Kulkarni K, Fang ZZ, Yang R, Girshov V. Titanium for automotive applications: challenges and opportunities in materials and processing. JOM. 2012;64:553-564. 
[7] Faller K, Froes FH. Titanium in automobiles. In: Froes FH, Haake SJ, editors. Materials and science in sports. Warrendale (PA): TMS; 2001. pp. 47-56.

[8] Montgomery JS, Wells MGH. Titanium armor applications in combat vehicles. JOM. 2001;53:29-32.

[9] Titanium Metals Corporation. Available from: http://www.timet.com.

[10] Diamanti MV, Del Curto B, Masconale V, Passaro C, Pedeferri MP. Anodic coloring of titanium and its alloy for jewels production. Color Res Appl. 2012;37:384-390.

[11] Hassel AW, Diesing D. Breakdown of ultrathin anodic valve metal oxide films in metalinsulator-metal contacts compared with metal-insulator-electrolyte contacts. Thin Solid Films. 2002;414:296-303.

[12] Vanhumbeeck JF, Proost J. Current understanding of Ti anodization: functional, morphological, chemical and mechanical aspects. Corrosion Rev. 2009;27:117-194.

[13] Ohtsuka T, Nomura N. The dependence of the optical property of Ti anodic oxide film on its growth rate by ellipsometry. Corrosion Sci. 1997;39:1253-1263.

[14] Van Gils S, Mast P, Stijns E, Terryn E. Colour properties of barrier anodic oxide films on aluminium and titanium studied with total reflectance and spectroscopic ellipsometry. Surf Coating Technol. 2004;185:303-310.

[15] Schroth S, Schneider M, Mayer-Uhma T, Michaelis A, Klemm V. Investigation of thin oxide films on titanium for capacitor applications. Surf Interface Anal. 2008;40:850-852.

[16] Kalra KC, Singh M. Formation and breakdown characteristics of anodic oxide films on valve materials. Indian J Chem. 1997;36:216-218.

[17] Dyer CK, Leach JSL. Breakdown and efficiency of anodic oxide growth on titanium. J Electrochem Soc. 1978;125:1032-1038.

[18] Diamanti MV, Pedeferri MP. Effect of anodic oxidation parameters on the titanium oxides formation. Corrosion Sci. 2007;49:939-948.

[19] Habazaki H, Uozumi M, Konno H, Shimizu K, Skeldon P, Thompson GE. Crystallization of anodic titania on titanium and its alloys. Corrosion Sci. 2003;45:2063-2073.

[20] Brown SD, Wirtz GP. Formation of ceramic coatings by anodic spark deposition. J Electrochem Soc. 1986;133:C92-C93.

[21] Yerokhin AL, Nie X, Leyland A, Matthews A, Dowey SJ. Plasma electrolysis for surface engineering. Surf Coating Technol. 1999;122:73-93.

[22] Krysmann W, Kurze P, Dittrich KH, Schneider HG. Structure and properties of ANOF layers. Cryst Res Technol. 1984;19:93-99.

[23] Teh TH, Berkani A, Mato S, Skeldon P, Thompson GE, Habazaki H, Shimizu K. Initial stages of plasma electrolytic oxidation of titanium. Corrosion Sci. 2003;45:2757-2768.

[24] Diamanti MV, Sebastiani M, Mangione V, Del Curto B, Pedeferri MP, Bemporad E, Cigada A, Carassiti F. Multi-step anodizing on Ti6Al4V components to improve tribomechanical performances. Surf Coating Technol. 2013;227:19-27.

[25] Zwilling V, Darque-Ceretti E. Characterization of porous and compact oxide films on titanium and Ti-6Al-4V. Ann Chim-Sci Mat. 1997;22:481-493.

[26] Zwilling V, Darque-Ceretti E, Boutry-Forveille A, David D, Perrin MY, Aucouturier M. Structure and physicochemistry of anodic oxide films on titanium and TA6V alloy. Surf Interface Anal. 1999;27:629-637.

[27] Gong D, Grimes CA, Varghese OK, Chen Z, Hu W, Dickey EC. Titanium oxide nanotube arrays prepared by anodic oxidation. J Mater Res. 2001;16:3331-3334.

[28] Zhou X, Nguyen NT, Özkan S, Schmuki P. Anodic $\mathrm{TiO}_{2}$ nanotube layers: why does selforganized growth occur - a mini review. Electrochem Commun. 2014;46:157-162.

[29] Roy P, Berger S, Schmuki P. $\mathrm{TiO}_{2}$ nanotubes: synthesis and applications. Angew Chem. 2011;50:2904-2939. 
[30] Mor GK, Varghese OK, Paulose M, Shankar K, Grimes CA. A review on highly ordered, vertically oriented $\mathrm{TiO}_{2}$ nanotube arrays: fabrication, material properties, and solar energy applications. Solar Energy Mater Solar Cells. 2006;90:2011-2075.

[31] Macak JM, Albu SP, Schmuki P. Towards ideal hexagonal self-ordering of $\mathrm{TiO}_{2}$ nanotubes. Rapid Res Lett. 2007;1:181-183.

[32] Beranek R, Hildebrand H, Schmuki P. Self-organized porous titanium oxide prepared in $\mathrm{H}_{2} \mathrm{SO}_{4} / \mathrm{HF}$ electrolytes. Electrochem. Solid-State Lett. 2003;6:B12.

[33] Diamanti MV, Codeluppi S, Cordioli A, Pedeferri MP. Effect of thermal oxidation on titanium oxides' characteristics. J Exp Nanosci. 2009;4:365-372.

[34] Perez del Pino A, Fernandez-Pradas JM, Serra P, Morenza JL. Coloring of titanium through laser oxidation: comparative study with anodising. Surf Coating Technol. 2004;187:106-112.

[35] Kuehni RG, Schwartz A. Color ordered: a survey of color systems from antiquity to the present. New York: Oxford University Press; 2007.

[36] Macleod HA. Basic theory, in thin-film optical filters. 3rd ed. Bristol: Institute of Physics; 2001.

[37] Fujishima A, Honda K. Electrochemical photolysis of water at a semiconductor electrode. Nature. 1972;238:37-38.

[38] Szymanski P, El-Sayed MA. Some recent developments in photoelectrochemical water splitting using nanostructured $\mathrm{TiO}_{2}$ : a short review. Theor Chem Acc. 2012;131:1202-1215.

[39] Nakata K, Fujishima A. $\mathrm{TiO}_{2}$ photocatalysis: design and applications. J Photochem Photobiol C. 2012;13:169-189.

[40] Zhang L, Dillert R, Bahnemann D, Vormoor M. Photo-induced hydrophilicity and selfcleaning: models and reality. Energy Environ Sci. 2012;5:7491-7507.

[41] Wang R, Hashimoto K, Fujishima A, Chikuni M, Kojima E, Kitamura A, Shimohigoshi M, Watanabe T. Light-induced amphiphilic surfaces. Nature. 1997;338:431-432.

[42] Paramasivam I, Jha H, Liu N, Schmuki P. A review of photocatalysis using self-organized $\mathrm{TiO}_{2}$ nanotubes and other ordered oxide nanostructures. Small. 2012;8:3073-3103.

[43] Oh HJ, Lee JH, Chi CS. Photocatalytic characteristics of titania thin film prepared by micro arc oxidation. Key Eng Mater. 2013;543:141-144.

[44] Diamanti MV, Ormellese M, Marin E, Lanzutti A, Mele A, Pedeferri MP. Anodic titanium oxide as immobilized photocatalyst in UV or visible light devices. J Hazard Mater. 2011;186:2103-2109.

[45] Xu J, Ao Y, Chen M, Fu D. Photoelectrochemical property and photocatalytic activity of Ndoped $\mathrm{TiO}_{2}$ nanotube arrays. Appl Surf Sci. 2010;256:4397-4401.

[46] Arjunan TV, Senthil TS. Review: dye sensitised solar cells. Mater Technol. 2013;28:9-14.

[47] Zhang Y, Ma Q-B, Gao L, Hensen EJM. Preparation and photoelectrochemical properties of nitrogen doped nanotubular $\mathrm{TiO}_{2}$ arrays. Appl Surf Sci. 2013;282:174-180.

[48] Cao L, Wu C, Hu Q, Jin T, Chi B, Pu J, Jian L. Double-layer structure photoanode with $\mathrm{TiO}_{2}$ nanotubes and nanoparticles for dye-sensitized solar cells. J Am Ceram Soc. 2013;96:549-554.

[49] Jena A, Mohanty SP, Kumar P, Naduvath J, Gondane V, Lekha P, Das J, Narula HK, Mallick S, Bhargava P. Dye sensitized solar cells: a review. Trans Indian Ceramic Soc. 2012;71:1-16.

[50] Liu G, Hoivik N, Wang X, Lu S, Wang K, Jakobsen H. Photoconductive, free-standing crystallized $\mathrm{TiO}_{2}$ nanotube membranes. Electrochim Acta. 2013;93:80-86.

[51] Perillo PM, Rodríguez DF. The gas sensing properties at room temperature of $\mathrm{TiO}_{2}$ nanotubes by anodization. Sensors Actuators B. 2012;171-172:639-643.

[52] Grimes CA, Ong KG, Varghese OK, Yang X, Mor G, Paulose M, Dickey EC, Ruan C, Pishko MV, Kendig JW, Mason AJ. A sentinel sensor network for hydrogen sensing. Sensors. 2003;3:69-82.

[53] Huyen DN, Tung NT, Thien ND, Thanh LH. Effect of $\mathrm{TiO}_{2}$ on the gas sensing features of $\mathrm{TiO}_{2} /$ PANi nanocomposites. Sensors. 2011;11:1924-1931. 
[54] Tian WC, Ho YH, Chou CH. Photoactivated $\mathrm{TiO}_{2}$ gas chromatograph detector for diverse chemical compounds sensing at room temperature. IEEE Sensors J. 2013;13:1725-1729.

[55] Albertin KF, Valle MA, Pereyra I. Study of MOS capacitors with $\mathrm{TiO}_{2}$ and $\mathrm{SiO}_{2} / \mathrm{TiO}_{2}$ gate dielectric. J Integr Circuits Syst. 2007;2:89-93.

[56] Sheen J, Li CY, Ji LW, Mao WL, Liu W, Chen CA. Measurements of dielectric properties of $\mathrm{TiO}_{2}$ thin films at microwave frequencies using an extended cavity perturbation technique. J Mater Sci: Mater Electron. 2010;21:817-821.

[57] Ben Omar M, Matoussi A. Dielectric and conductivity investigations of rutile titanium dioxide single crystals. In: Annual Report Conference on Electrical Insulation and Dielectric Phenomena (CEIDP); 2012; Montreal. pp. 467-470.

[58] $\mathrm{Sim} \mathrm{H}$, Samantaray $\mathrm{CB}$, Hwang $\mathrm{H}$. The $\mathrm{HfSi}_{\mathrm{x}} \mathrm{O}_{\mathrm{y}}$ interfacial layer effect on improving electrical characteristics of ultrathin high- $\kappa \mathrm{TiO}_{2}$ gate dielectric. Electrochem Solid State Lett. 2013;8: F5-F7.

[59] Kokubo T, Miyaji F, Kim HM, Nakamura T. Spontaneous formation of bonelike apatite layer on chemically treated titanium metals. J Am Ceramic Soc. 1996;79:1127-1129.

[60] Zhao JM, Tsuru K, Hayakawa S, Osaka A. Modification of Ti implant surface for cell proliferation and cell alignment. J Biomed Mater Res A. 2008;84A:988-993.

[61] Giavaresi G, Fini M, Chiesa R, Giordano C, Sandrini E, Bianchi AE, Ceribelli P, Giardino R. A novel multiphase anodic spark deposition coating for the improvement of orthopedic implant osseointegration: an experimental study in cortical bone of sheep. J Biomed Res A. 2008;85:1022-1031.

[62] Sollazzo V, Palmieri A, Pezzetti F, Scarano A, Martinelli M, Scapoli L, Massari L, Brunelli G, Caramelli E, Carinci F. Genetic effect of anatase on osteoblast-like cells. J Biomed Mater Res B. 2008;85B:29-36.

[63] Yang B, Uchida M, Kim UM, Zhang X, Kokubo T. Preparation of bioactive titanium metal via anodic oxidation treatment. Biomaterials. 2004;25:1003-1010.

[64] Albu SP, Ghicov A, Macak JM, Hahn R, Schmuki P. Self-organized, free-standing $\mathrm{TiO}_{2}$ nanotube membrane for flow-through photocatalytic applications. Nano Lett. 2007;7:1286-1289.

[65] Sjöström T, Brydone AS, Meek RMD, Dalby MJ, Su B, McNamara LE. Titanium nanofeaturing for enhanced bioactivity of implanted orthopedic and dental device. Nanomedicine. 2013;8:89-104.

[66] Lavenus S, Trichet V, Le Chevalier S, Hoornaert A, Louarn G, Layrolle P. Cell differentiation and osseointegration influenced by nanoscale anodized titanium surfaces. Nanomedicine. 2012;7:967-980.

[67] Draghi L, Cigada A. Nanostructured surfaces for biomedical applications. Part I: nanotopography. J Appl Biomater Biomech. 2007;5:61-69.

[68] Mendonca G, Mendonca DBS, Simões LGP, Araújo AL, Leite ER, Duarte WR, Cooper LF, Aragão FJL. Nanostructured implant surface effect on osteoblast specific gene expression and bone-to-implant contact in vivo. Mater Sci Eng C. 2011;31:1809-1818.

[69] Zhao L, Liu L, Wu Z, Zhang Y, Chu PK. Effects of micropitted/nanotubular titania topographies on bone mesenchymal stem cell osteogenic differentiation. Biomaterials. 2012;33:2629-2641.

[70] Bressan E, Carraro A, Ferroni L, Gardin C, Sbricoli L, Guazzo R, Stellini E, Roman M, Pinton P, Sivolella S, Zavan B. Nanotechnology to drive stem cell commitment. Nanomedicine. 2013;8:469-483.

[71] Kummer K, Taylor E, Webster TJ. Biological applications of anodized $\mathrm{TiO}_{2}$ nanostructures: a review from orthopedic to stent applications. Nanosci Nanotech Lett. 2012;4:483-493.

[72] Guo J, Padilla RJ, Ambrose W, De Kok IJ, Cooper LF. Modification of $\mathrm{TiO}_{2}$ grit blasted titanium implants by hydrofluoric acid treatment alters adherent osteoblast gene expression in vitro and in vivo. Biomaterials. 2007;28:5418-5425. 
[73] Decuzzi P, Ferrari M. Modulating cellular adhesion through nanotopography. Biomaterials. 2010;31:173-179.

[74] Lan MY, Liu CP, Huang HH, Chang JK, Lee SW. Diameter-sensitive biocompatibility of anodic $\mathrm{TiO}_{2}$ nanotubes treated with supercritical $\mathrm{CO}_{2}$ fluid. Nanoscale Res Lett. 2013;8:150.

[75] Frandsen CJ, Brammer KS, Jin S. Nanotube surface for bone regeneration. Int J Biomater. 2013;2013:513680.

[76] Popat KC, Elgroth M, LaTempa TJ, Grimes CA, Desai TA. Decreased staphylococcus epidermis adhesion and increased osteoblast functionality on antibiotic-loaded titania nanotubes. Biomaterials. 2007;28:4880-4888.

[77] Balasundaram G, Yao C, Webster $\mathrm{TJ}$. $\mathrm{TiO}_{2}$ nanotubes functionalized with regions of bone morphogenetic protein-2 increases osteoblast adhesion. J Biomed Mater Res A. 2008;84A:447-453.

[78] Park J, Bauer S, von der Mark K, Schmuki P. Nanosize and vitality: $\mathrm{TiO}_{2}$ nanotube diameter directs cell fate. Nano Lett. 2007;7:1686-1691.

[79] Moseke C, Hage F, Vorndran E, Gburek U. $\mathrm{TiO}_{2}$ nanotube arrays deposited on Ti substrate by anodic oxidation and their potential as a long-term drug delivery system for antimicrobial agents. Appl Surf Sci. 2012;258:5399-5404.

[80] Song YY, Schmidt-Stein F, Bauer S, Schmuki P. Amphiphilic $\mathrm{TiO}_{2}$ nanotube arrays: an actively controllable drug delivery system. J Am Chem Soc. 2009;131:4230-4232.

[81] Gordienko PS, Kharchenko UV, Bulanova SB, Panin ES, Usol'tsev VK, Dostovalov VA. Physicochemical properties of coatings formed on titanium by microarc oxidation with energy regulation in breakdown zones. Prot Metals. 2008;44:475-478.

[82] Rudnev VS, Yarovaya TP, Kon'shin GI, Gordienko PS. Anodic spark deposition of P, Me(II) or $\mathrm{Me}(\mathrm{III})$ containing coatings on aluminum and titanium alloys in electrolytes with polyphosphate complexes. Prot Metals. 2003;39:160-165.

[83] Liu Y, Wang X, Yang F, Yang X. Excellent antimicrobial properties of mesoporous anatase $\mathrm{TiO}_{2}$ and $\mathrm{Ag} / \mathrm{TiO}_{2}$ composite films. Microporous Mesoporous Mater. 2008;114:431-439.

[84] Song WH, Ryu HS, Hong SH. Antibacterial properties of Ag (or Pt)-containing calcium phosphate coatings formed by micro-arc oxidation. J Biomed Mater A. 2009;88A:246-254.

[85] Necula BS, Apachitei I, Fratila-Apachitei LE, van Langelaan EJ, Duszczyk J. Titanium bone implants with superimposed micro/nano-scale porosity and antibacterial capability. Appl Surf Sci. 2013;273:310-314.

[86] Magagnin L, Bernasconi R, Ieffa S, Diamanti MV, Pezzoli D, Candiani G, Pedeferri MP. Photocatalytic and antimicrobial coatings by electrodeposition of silver/ $\mathrm{TiO}_{2}$ nanocomposites. ECS Trans. 2013;45:1-6.

[87] Boenigk J, Beisser D, Zimmermann S, Bock C, Jakobi J, Grabner D, Großmann L, Rahmann S, Barcikowski S, Sures B. Effects of silver nitrate and silver nanoparticles on a planktonic community: general trends after short-term exposure. PLoS ONE. 2014;9:e95340.

[88] Kvitek L, Panacek A, Prucek R, Soukupova J, Vanickova M, Kolar M, Zboril R. Antibacterial activity and toxicity of silver - nanosilver versus ionic silver. J Phys Conf Ser. 2011;304:012029.

[89] Durán N, Marcato PD, De Conti R, Alves OL, Costa FTM, Brocchi M. Potential use of silver nanoparticles on pathogenic bacteria, their toxicity and possible mechanisms of action. $\mathrm{J}$ Braz Chem Soc. 2010;21:949-959.

[90] Ishizawa H, Ogino M. Formation and characterization of anodic titanium oxide films containing Ca and P. J Biomed Mater Res. 1995;29:65-72.

[91] Chiesa R, Sandrini E, Santin M, Rondelli G, Cigada A. Osteointegration of titanium and its alloys by anodic spark deposition and other electrochemical techniques: a review. J Appl Biomater Biomech. 2003;1:91-107.

[92] Ishizawa H, Ogino M. Hydrothermal precipitation of hydroxyapatite on anodic titanium oxide films containing Ca and P. J. Mater Sci. 1999;34:5893-5898. 
[93] Sandrini E, Chiesa R, Rondelli G, Santin M, Cigada A. A novel biomimetic treatment for an improved osteointegration of titanium. J Appl Biomater Biomech. 2003;1:33-42.

[94] Lee CK. Fabrication, characterization and wear corrosion testing of bioactive hydroxyapatite/ nano- $\mathrm{TiO}_{2}$ composite coatings on anodic Ti-6Al-4V substrate for biomedical applications. Mater Sci Eng B. 2012;177:810-818.

[95] Sun J, Han Y, Huang X. Hydroxyapatite coating prepared by micro-arc oxidation in Ca- and P-containing electrolytes. Surf Coating Technol. 2005;201:5655-5658.

[96] Shibata Y, Suzuki D, Omori S, Tanaka R, Murakami A, Kataoka Y, Baba K, Kamijo R, Miyazaki $\mathrm{T}$. The characteristics of in vitro biological activity of titanium surfaces anodically oxidized in chloride solutions. Biomaterials. 2010;31:8546-8555.

[97] Deng J, Arimoto T, Shibata Y, Omori S, Miyazaki T, Igarashi T. Role of chloride formed on anodized titanium surfaces against an oral microorganism. $\mathbf{J}$ Biomater Appl. 2010;25:179-189.

[98] Molinari A, Straffelini G, Tesi B, Bacci T. Dry sliding wear mechanisms of the $\mathrm{Ti}_{6} \mathrm{Al}_{4} \mathrm{~V}$ alloy. Wear. 1997;208:105-112.

[99] Romankov SE, Mukashev BN, Ermakov EL, Muhamedishina DN. Structural formation of aluminide phases on titanium substrate. Surf Coating Technol. 2004;180:280-285.

[100] Yoshihara M, Kim YW. Oxidation behavior of gamma alloys designed for high temperature applications. Intermetallics. 2005;13:952-958.

[101] Veiga C, Devim JP, Loureiro AJR. Properties and applications of titanium alloys: a brief review. Rev Adv Mater Sci. 2013;32:133-148.

[102] Dalmiglio M, Schaaff P, Holzwarth U, Chiesa R, Rondelli G. The effect of surface treatments on the fretting behavior of Ti-6Al-4V alloy. J Biomed Mater Res B. 2008;86B:407-416.

[103] Fei C, Hai Z, Chen C, Yangjian X. Study on the tribological performance of ceramic coatings on titanium alloy surfaces obtained through microarc oxidation. Prog Org Coatings. 2009;64:264-267.

[104] Wu XQ, Xie FQ, Hu ZC, Wang L. Effects of additives on corrosion and wear resistance of micro-arc oxidation coatings on TiAl alloy. Trans Nonferrous Metals Soc China. 2010;20:1032-1036.

[105] Yetim AF. Investigation of wear behavior of titanium oxide films, produced by anodic oxidation, on commercially pure titanium in vacuum conditions. Surf Coating Technol. 2010;205:1757-1763.

[106] Rudnev VS, Yarovaya TP, Kon'shin VV, Gordienko PS. Anodic spark coatings on titanium and AMLIM Alloy from baths containing aluminum polyphosphate complexes. Prot Metals. 2003;39:160-165.

[107] Rudnev VS, Medkov MA, Kilin KN, Ustinov AYu, Belobeletskaya MV, Steblevskaya NI, Mutylina IN, Zherebtsov TO. Plasma-electrolytic formation of Ta-containing oxide coatings on titanium. Their composition and properties. Prot Metals Phys Chem Surf. 2013;49:717-723.

[108] Ravi Shankar A, Kamachi Mudali U. Refractory metal coatings on titanium to improve corrosion resistance in nitric acid medium. Surf Coating Technol. 2013;235:155-164.

[109] Mo J, Zhang Y, Zu Q, Lamson JJ, Zhao R. Photocatalytic purification of volatile organic compounds in indoor air: A literature review. Atmos Environ. 2009;43:2229-2246.

[110] Nagaveni K, Hegde MS, Madras G. Structure and photocatalytic activity of $\operatorname{Ti}_{1-x} M_{x} \mathrm{O}_{2-\delta}(\mathrm{M}=$ $\mathrm{W}, \mathrm{V}, \mathrm{Ce}, \mathrm{Zr}, \mathrm{Fe}$, and $\mathrm{Cu}$ ) synthesized by solution combustion method. J Phys Chem $\mathrm{B}$. 2004;108:20204-20212.

[111] Umebayashi T, Yamaki T, Itoh H, Asai K. Analysis of electronic structures of $3 \mathrm{~d}$ transition metal-doped $\mathrm{TiO}_{2}$ based on band calculations. J Phys Chem Solids. 2002;63:1909-1920.

[112] Rudnev VS, Wybornov S, Lukiyanchuk IV, Staedler T, Jiang X, Ustinov AYu, Vasilyeva MS. Thermal behavior of Ni- and $\mathrm{Cu}$-containing plasma electrolytic oxide coatings on titanium. Appl Surf Sci. 2012;258:8667-8672. 
[113] Vasilyeva MS, Rudnev VS, Wiedenmann F, Wybornov S, Yarovaya P, Jiang X. Thermal behavior and catalytic activity in naphthalene destruction of $\mathrm{Ce}-\mathrm{Zr}$ - and $\mathrm{Mn}$-containing oxide layers on titanium. Appl Surf Sci. 2011;258:719-726.

[114] Lukiyanchuk IV, Rudnev VS, Chernykh IV, Malyshev IV, Tyrina LM, Adigamova MV. Composites with transition metal oxides on aluminum and titanium and their activity in $\mathrm{CO}$ oxidation. Surf Coating Technol. 2013;231:433-438.

[115] Yang K, Dai Y, Huang B, Whangbo MH. Density functional characterization of the band edges, the band gap states, and the preferred doping sites of halogen-doped $\mathrm{TiO}_{2}$. Chem Mater. 2008;20:6528-6534.

[116] Park JH, Kim S, Bard AJ. Novel carbon-doped $\mathrm{TiO}_{2}$ nanotube arrays with high aspect ratios for efficient solar water splitting. Nano Lett. 2006;6:24-28.

[117] Asahi R, Morikawa T, Ohwaki T, Aoki K, Taga Y. Visible-light photocatalysis in nitrogendoped titanium oxides. Science. 2001;293:269-271.

[118] Nakamura R, Tanaka T, Nakato Y. Mechanism for visible light responses in anodic photocurrents at N-doped $\mathrm{TiO}_{2}$ film electrodes. J Phys Chem B. 2004;108:10617-10620.

[119] Beranek R, Kisch H. Surface-modified anodic $\mathrm{TiO}_{2}$ films for visible light photocurrent response. Electrochem Commun. 2007;9:761-766.

[120] Chua LO. Memristor - the missing circuit element. IEEE Trans Circuit Theory. 1971;18:507-519.

[121] Miller K, Nalwa KS, Bergerud A, Neihart NM. Memristive behavior in thin anodic titania. IEEE Electron Device Lett. 2010;31:737-739.

[122] Diamanti MV, Souier T, Stefancich M, Chiesa M, Pedeferri MP. Probing anodic oxidation kinetics and nanoscale heterogeneity within $\mathrm{TiO}_{2}$ films by conductive atomic force microscopy and combined techniques. Electrochim Acta. 2014;129:203-210.

[123] Strukov DB, Snider GS, Stewart DR, Williams RS. The missing memristor found. Nature. 2008;453:80-84.

[124] Thomas A. Memristor-based neural networks. J Phys D. 2013;46:093001.

[125] Evans UR. The colors due to thin films on metals. Proc Roy Soc London Ser A. 1925;107:228-237.

[126] Sul Y-T, Johansson CB, Jeong Y, Albrektsson T. The electrochemical oxide growth behaviour on titanium in acid and alkaline electrolytes. Med Eng Phys. 2001;23:329-346.

[127] Velten D, Biehl V, Aubertin F, Valeske B, Possart W, Breme J. Preparation of $\mathrm{TiO}_{2}$ layers on cp-Ti and Ti6Al4V by thermal and anodic oxidation and by sol-gel coating techniques and their characterization. J Biomed Mat Res. 2001;59:18-28.

[128] Cotton JB, Mayfield PCS. Decorative finishes on titanium. Trans Inst Metal Finishing. 1967;45:201.

[129] Pedeferri P. Movements on titanium. Milan: CLUP; 1984.

[130] Titani Preziosi exhibition. Available from: http://www.titanipreziosi.it

[131] Richard RG. The relevance of implant surfaces in hand fracture fixation. In: Herren DB, Nagy L, Campbell DA, editors. Osteosynhtesis in the hand: current concepts. FESSH instructional course. Basel: Karger; 2008. pp. 20-30. 